\section{Lupus Cerebritis}

Elliot J. Roth

Northwestern University, Feinberg School of Medicine, Physical Medicine and Rehabilitation, Chicago, IL, USA

\section{Synonyms}

CNS lupus

\section{Definition}

Lupus cerebritis is an important complication of systemic lupus erythematosus, characterized by cerebral vasculitis or inflammation of the blood vessels in the brain. This may result in stroke or other symptoms including headaches, seizures, psychosis, dementia, or peripheral neuropathy.
Stroke occurs in 5-20\% of all patients with systemic lupus. It is treated by the control of systemic lupus and by the use of anti-inflammatory medications such as steroids.

\section{Cross-References}

- Cerebral Angiitis

- Collagen Vascular Disease

Vasculitis

\section{References and Readings}

Jennekens, F. G., \& Kater, L. (2002). The central nervous system in systemic lupus erythematosus. Part 1. Clinical syndromes: A literature investigation. Rheumatology (Oxford), 41(6), 605-618.

Muscal, E., \& Brey, R. L. (2010). Neurologic manifestations of systemic lupus erythematosus in children and adults. Neurologic Clinics, 28, 61-73. 